\title{
Development and In vitro Evaluation of Flurbiprofen Microcapsules Prepared by Modified Solvent Evaporation Technique
}

\author{
Muhammad Farhan Sohail ${ }^{1}$, Pervaiz Akhtar Shah ${ }^{2}$, Imran Tariq ${ }^{2 *}$, Syed Saeed- \\ ul-Hassan ${ }^{2}$, Umair Amin ${ }^{2}$, Syed Atif Raza ${ }^{2}$, Tariq Saeed ${ }^{2}$, Misbah Sultana ${ }^{2}$ and \\ Najam ul Hassan Jawa ${ }^{2}$ \\ ${ }^{1}$ Riphah Institute of Pharmaceutical Sciences, Riphah international University, Islamabad, Pakistan -54000; ${ }^{2}$ University College \\ of Pharmacy, University of the Punjab, Lahore, Pakistan 54000
}

*For correspondence: Email: imran_1982@hotmail.com; Tel: 0092-322-4218583, 42-36156006

\begin{abstract}
Purpose: To develop modified release microcapsules of flurbiprofen for sustained release and reduced gastrointestinal side effects.

Method: A co-polymer containing Eudragit RS 100 and hydroxypropyl methylcellulose (HPMC) in different drug/co-polymer ratios was used for microencapsulation of flurbiprofen by modified emulsion solvent evaporation (MESE) technique. The microcapsules were evaluated by $x$-ray diffraction (XRD), differential scanning calorimetry (DSC), Fourier transform infra-red spectroscopy (FTIR) and scanning electron microscopy (SEM). Dissolution study was conducted in $0.1 \mathrm{M} \mathrm{HCl}$ for $2 \mathrm{~h}$ and phosphate buffer $(\mathrm{pH}$ 7.4) for $8 \mathrm{~h}$, and the resulting data were analyzed by various pharmacokinetic models.

Results: The data obtained from pre-formulation confirmed the purity of flurbiprofen. Particle size, flow rate and angle of repose showed good flow properties. FTIR and DSC confirmed the absence of incompatibilities among the drug and polymers. XRD of flurbiprofen showed characteristic sharp peaks confirming the crystalline nature of the drug which, however, decreased slightly in the formulation. SEM revealed that microencapsules of spherical shape and rough surface were produced at lower drug to copolymer ratio in contrast to the higher ratio which produced irregular microcapsules. Encapsulation efficiency was $65-85 \%$ while regression coefficient (R2) values from kinetic analysis showed that release followed Korsmeyer-Peppas model with " $n$ " > 1 indicating release mechanism followed super case II transport.

Conclusion: MESE technique using Eudragit RS 100/HPMC polymer blend is a suitable approach to development of modified release flurbiprofen microcapsules.
\end{abstract}

Keywords: Microcapsules, Eudragit RS-100, Hydroxypropyl methylcellulose, Emulsion solvent evaporation, Flurbiprofen, Sustained drug release

Tropical Journal of Pharmaceutical Research is indexed by Science Citation Index (SciSearch), Scopus, International Pharmaceutical Abstract, Chemical Abstracts, Embase, Index Copernicus, EBSCO, African Index Medicus, JournalSeek, Journal Citation Reports/Science Edition, Directory of Open Access Journals (DOAJ), African Journal Online, Bioline International, Open-J-Gate and Pharmacy Abstracts

\section{INTRODUCTION}

A well designed modified drug delivery system can overcome many of the problems of conventional dosage forms and enhance the therapeutic efficacy of the administered drug [1].
Microencapsulation is one of such techniques by which solid, liquid or even gas molecules can be coated with a very thin wall material converting them to free flowing particles [2]. 
Eudragit RS 100 is a polymethacrylate, with a chemical names such as poly (ethyl acrylate, methyl methacrylate, trimethylammonioethyl methacrylate chloride), having low amount of quaternary ammonium attached which gives $\mathrm{pH}$ independent permeability and renders the film form by RS 100 less permeable to water [3]. It is a versatile polymer with a wide range of applications in development of transdermal delivery system, modified release dosage forms, ocular formulations, oral delivery system and Nano particles formulation [4]. HPMC is a white, colourless, odorless powder which is available in various forms and grades [3]. It is a multipurpose material having wide $\mathrm{pH}$ stability and used as binder, coating agent, suspending agent, emulsifying agent, release retardant and thickening agent in different formulations depending on the grade and concentration used $[3,5]$.

Flurbiprofen, a, 2-(2-flurobiphenyl-4yl) propionic acid belongs to a group of non-steroidal antiinflammatory drugs used for the treatment of mild to moderate pain [6]. They impart their action by inhibiting the synthesis of prostaglandins involved in pain and inflammation [7]. There are many methods for microencapsulation and selection of method depends on hydrophilicity or hydrophobicity of the drug [8].

The present work was aimed to study the development and evaluation of microencapsulated flurbiprofen by modified solvent evaporation technique using varying polymer ratios, for modified release of the drug.

\section{EXPERIMENTAL}

\section{Materials}

Eudragit RS 100 and HPMC 4000 cps were gifts by Surge Laboratories Pvt. Ltd. Lahore, Pakistan. Flurbiprofen was a gift from Schazoo Laboratories Pvt. Ltd. Lahore Pakistan. Acetone, $\mathrm{n}$-hexane, petroleum ether $40-60{ }^{\circ} \mathrm{C}$ (research grade, Merck), liquid paraffin (commercial grade, UCP Laboratories, Lahore, Pakistan), Span 20 (Pdh Pharmaceuticals, Lahore Pakistan), and magnesium stearate (commercial grade, purchased from a local store, Lahore, Pakistan) were also used in this study.

\section{Formulation of microcapsules}

A total of twelve formulations with varying polymer ratios were prepared as stated in Table 1. For this purpose the weighed amount of polymer was dissolved in $25 \mathrm{ml}$ acetone; by stirring the mixture at $600 \mathrm{rpm}$ for $15 \mathrm{~min}$, using magnetic stirrer. The weighed amount of flurbiprofen was dispersed in liquid paraffin already containing $1 \%$ w/w span 20 and magnesium stearate while stirring at $800 \mathrm{rpm}$ for $15 \mathrm{~min}$. The polymer solution was then added slowly to this dispersion using burette. After $10-$ $15 \%$ of polymer addition, n-hexane was added to the liquid paraffin mixture. The mixture was stirred at $800 \mathrm{rpm}$ at room temperature $(25 \pm 2$ ${ }^{\circ} \mathrm{C}$ ) for $4 \mathrm{~h}$ until the acetone and $\mathrm{n}$-hexane were completely evaporated. Liquid paraffin was decanted off, the microcapsules collected, washed with $\mathrm{n}$-hexane thrice to remove any remaining oil phase, and then dried at room temperature for at least $12 \mathrm{~h}$. The formulations were stored in an air-tight glass container and placed in a desiccator containing silica beads. The same procedure was done for all the formulations.

\section{In vitro characterization}

Percentage yield, actual drug loading, encapsulation efficiency were determined as previously described [8].

\section{Scanning electron microscopy (SEM)}

Surface morphology was performed by using JEOL JSM 6480, Japan, with image analysis system. The sample was prepared by fixing the prepared microcapsules to double sided conducting tape, which was fixed to a brass specimen stub coated with gold. The samples were run at accelerating voltage of $15 \mathrm{kV}$ at high vacuum mode.

\section{Fourier transformed infrared (FTIR) spectroscopy}

The compatibility of flurbiprofen and polymers was studied through FTIR analysis. The FTIR study was performed using Nicolet FTIR 6700 with zinc selenide optics, Thermoscientific, USA. For analysis, very small quantity of sample was placed on the lens of equipment directly with the help of spatula and pressure was applied through screwed up to the specified mark. The spectrum was recorded between $4000-500 \mathrm{~cm}^{-1}$.

\section{Differential scanning calorimetry (DSC)}

Thermal analysis was performed with DSC Q 2000, TA instruments, USA. The weighed amount $(10 \mathrm{mg})$ of sample was sealed in aluminum pan. The analysis was performed at nitrogen flow of $40 \mathrm{ml} / \mathrm{min}$ and scanning was done at the heating rate of $10{ }^{\circ} \mathrm{C} / \mathrm{min}$ from $25^{\circ} \mathrm{C}$ 
Table 1: Composition of microcapsule formulations

\begin{tabular}{llllll}
\hline Formulation code & Polymer ratio & $\begin{array}{l}\text { Drug: } \\
\text { polymer }\end{array}$ & $\begin{array}{l}\text { Drug } \\
(\mathbf{m g})\end{array}$ & $\begin{array}{l}\text { HPMC } \\
(\mathbf{m g})\end{array}$ & $\begin{array}{l}\text { Eudragit RS- } \\
\mathbf{1 0 0}(\mathbf{m g})\end{array}$ \\
\hline A1 & 75\% HPMC & $1: 0.5$ & 2000 & 750 & 250 \\
A2 & $25 \%$ Eudragit & $1: 1$ & 2000 & 1000 & 1000 \\
A3 & $1: 1.5$ & 2000 & 2250 & 750 \\
B1 & $1: 0.5$ & 2000 & 750 & 250 \\
B2 & $75 \%$ HPMC & $1: 1$ & 2000 & 1000 & 1000 \\
B3 & 25\% Eudragit & $1: 1.5$ & 2000 & 2250 & 750 \\
C1 & & $1: 0.5$ & 2000 & 750 & 250 \\
C2 & 75\% HPMC & $1: 1$ & 2000 & 1000 & 1000 \\
C3 & 25\% Eudragit & $1: 1.5$ & 2000 & 2250 & 750 \\
F1 & $1: 1$ & 2000 & 2000 & 0 \\
F2 & $100 \%$ HPMC & $1: 1$ & 2000 & 2000 & 0 \\
F3 & 100\% Eudragit & 0 & 100 & 0 & 0 \\
\hline
\end{tabular}

to $200{ }^{\circ} \mathrm{C}$ using empty aluminum pan as reference.

\section{Powder x-ray diffraction (PX-RD)}

Powder XRD was performed to check the effect of different formulation on crystallinity of the drug.

\section{In vitro dissolution studies}

The in vitro release of flurbiprofen was determined using USP dissolution apparatus type I with basket assembly. The weighed amount of microsphere equivalent to $100 \mathrm{mg}$ of flurbiprofen was filled in inert hard gelatin capsule and placed in basket of dissolution apparatus. For the first two hours the microspheres were run in acidic media using 900 $\mathrm{ml}$ of $0.1 \mathrm{M} \mathrm{HCl}$. The temperature was maintained at $37+0.5^{\circ} \mathrm{C}$ and the apparatus was set at $100 \mathrm{rpm}$. Samples were collected at predefined intervals, i.e., $15,30 \mathrm{~min}, 1 \mathrm{~h}$ and $2 \mathrm{~h}$. $10 \mathrm{ml}$ of sample was collected using a syringe and the sample was filtered using $0.45 \mu \mathrm{m}$ filter paper and was replaced with same amount of fresh acidic solution pre-warmed at $37^{\circ} \mathrm{C}$. After 2 $\mathrm{h}$, the dissolution media was replaced with 900 $\mathrm{ml}$ of phosphate buffer $\mathrm{pH} 7.4$ to perform further dissolution studies. Samples were collected at hourly intervals up to $12 \mathrm{~h}$ and then after $24 \mathrm{~h}$. All samples were diluted with phosphate buffer and analyzed at a wavelength of $247 \mathrm{~nm}$ spectrophotometrically (model UV 2550, Shimadzu, Japan).

\section{Release kinetics}

Dissolution data was analyzed using various kinetic models: zero order, first order, Higuchi's model, Hixon-Crowell and Korsmeyer-Peppas to determine the release kinetics of the formulations.

\section{Determination of similarity factor (f2)}

For comparison of the in vitro dissolution profiles of the standard reference drug (flurbiprofen, Ansaid $(8$ tablet) and the test drug formulations, similarity factor (f2) was determined. Its value ranges from $50-100$. Values $>50$ show dissimilarity while $<50$ indicate similarity in in vitro release drug profile [10].

$f_{2}=50+\log \{[1+(1 / n) ? t=1 * n(R t-T t) 2]-0.5 * 100\} \ldots(1)$ where Rt and $\mathrm{Tt}$ are the cumulative percentage dissolved at each of the selected ' $n$ ' time points of the reference and test product, respectively.

\section{Statistical analysis}

For statistical analysis, one-way ANOVA was performed to check the release profile using SPSS version 12.0. The level of significance was set at $p<0.05$.

\section{RESULTS}

\section{Drug loading and encapsulation efficiency}

Drug loading percentage showed maximum in formulation A3 (52.9\%) and least with C3 (25.79 $\%)$. As with an increase in drug polymer ratio drug loading decreased. Maximum encapsulation is also shown by $\mathrm{A} 3(85 \%)$ and minimum by $\mathrm{C} 3$ $(65 \%)$. As Eudragit proportion increased in the co-polymer blend, drug loading decreased (Table 2).

\section{Yield}

The yield of the formulations was maximum for C2 (98 \%) and minimum for C3 (81\%) (Table 2). 
Table 2: Yield, drug loading and encapsulation efficiency of formulations

\begin{tabular}{lccc}
\hline Formulation & Yield (\%) & $\begin{array}{c}\text { \% Drug } \\
\text { loading (\%) }\end{array}$ & $\begin{array}{c}\text { Encapsulation } \\
\text { efficiency (\%) }\end{array}$ \\
\hline A1 & 86.000 & 52.935 & 84.696 \\
A2 & 88.567 & 38.141 & 76.280 \\
A3 & 91.967 & 28.647 & 71.613 \\
B1 & 84.775 & 45.340 & 72.544 \\
B2 & 92.325 & 33.473 & 66.950 \\
B3 & 86.250 & 28.014 & 70.038 \\
C1 & 85.000 & 42.967 & 68.744 \\
C2 & 32.600 & 32.761 & 65.520 \\
C3 & 80.860 & 25.799 & 64.500 \\
F1 & 88.100 & 33.552 & 67.100 \\
F2 & 86.975 & 30.783 & 61.570 \\
\hline
\end{tabular}
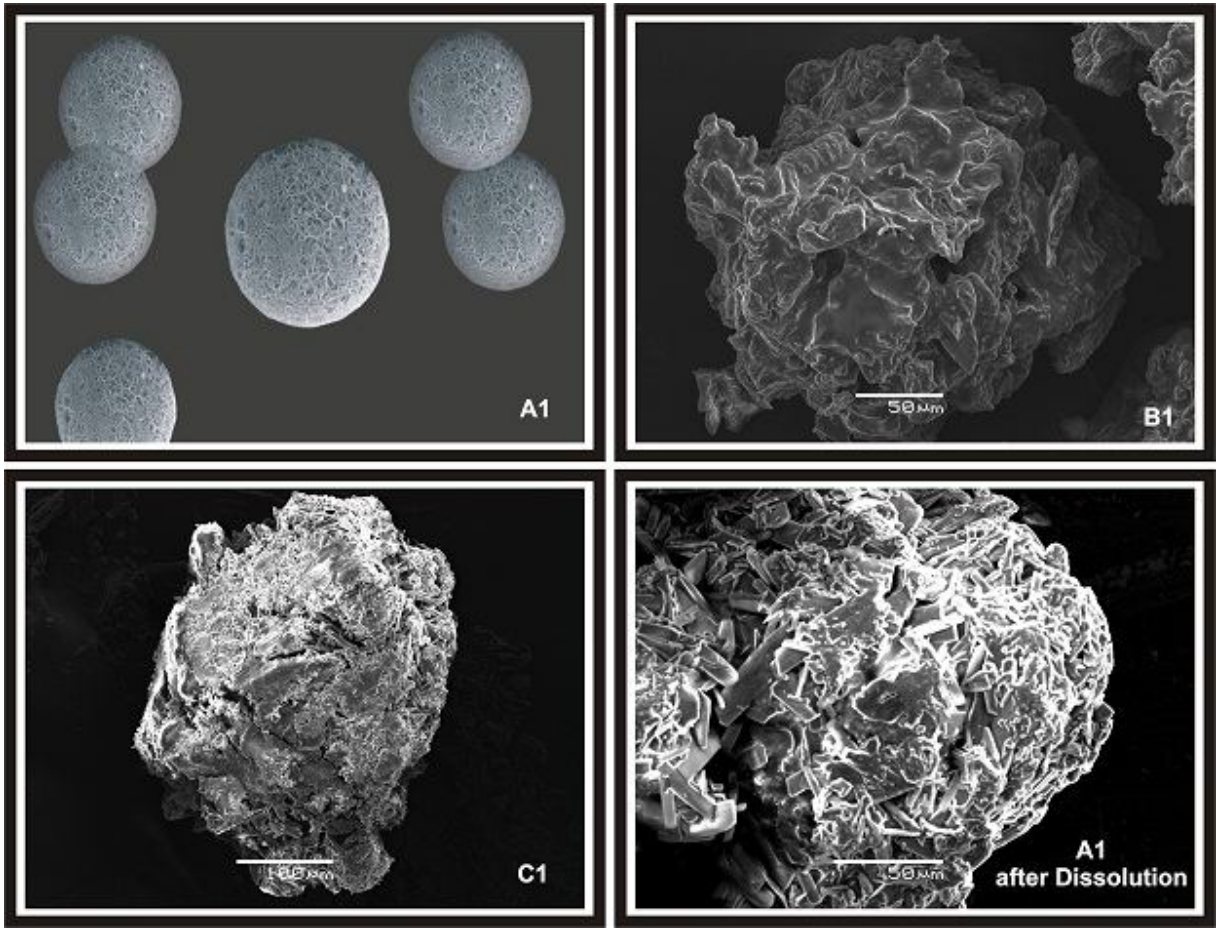

Figure 1: SEM of formulations $\mathrm{A} 1, \mathrm{~B} 1, \mathrm{C} 1$ and $\mathrm{A} 1$ after dissolution

\section{Scanning electron microscopy (SEM)}

SEM revealed that the particle size of microcapsules ranged from 10 to $50 \mu \mathrm{m}$. The microcapsules formed were of irregular in shape except for A1 which was spherical in shape with slightly rough surface It is observed that with an increase in polymer ratio, the surface became rough and irregular in shape. SEM analysis of microencapsules after $10 \mathrm{~h}$ dissolution showed surface erosion and diffusion mechanism as presence of channels on surface (Figure 1).

\section{Infrared spectra}

FTIR spectrum of flurbiprofen gives characteristic sharp peak at 1694.9 representing the presence of $(\mathrm{C}=\mathrm{O})$ carbonyl compound, peak at 1215.6 represents stretching of $(\mathrm{C}-\mathrm{F})$ and a characteristic broad peak of flurbiprofen in the range of $2,500-3,300 \mathrm{~cm}^{-1}$ due to hydrogen bonding. Spectra of formulation A1 showed the same absorbance pattern as the combination of drug and polymers (Figure 2). 


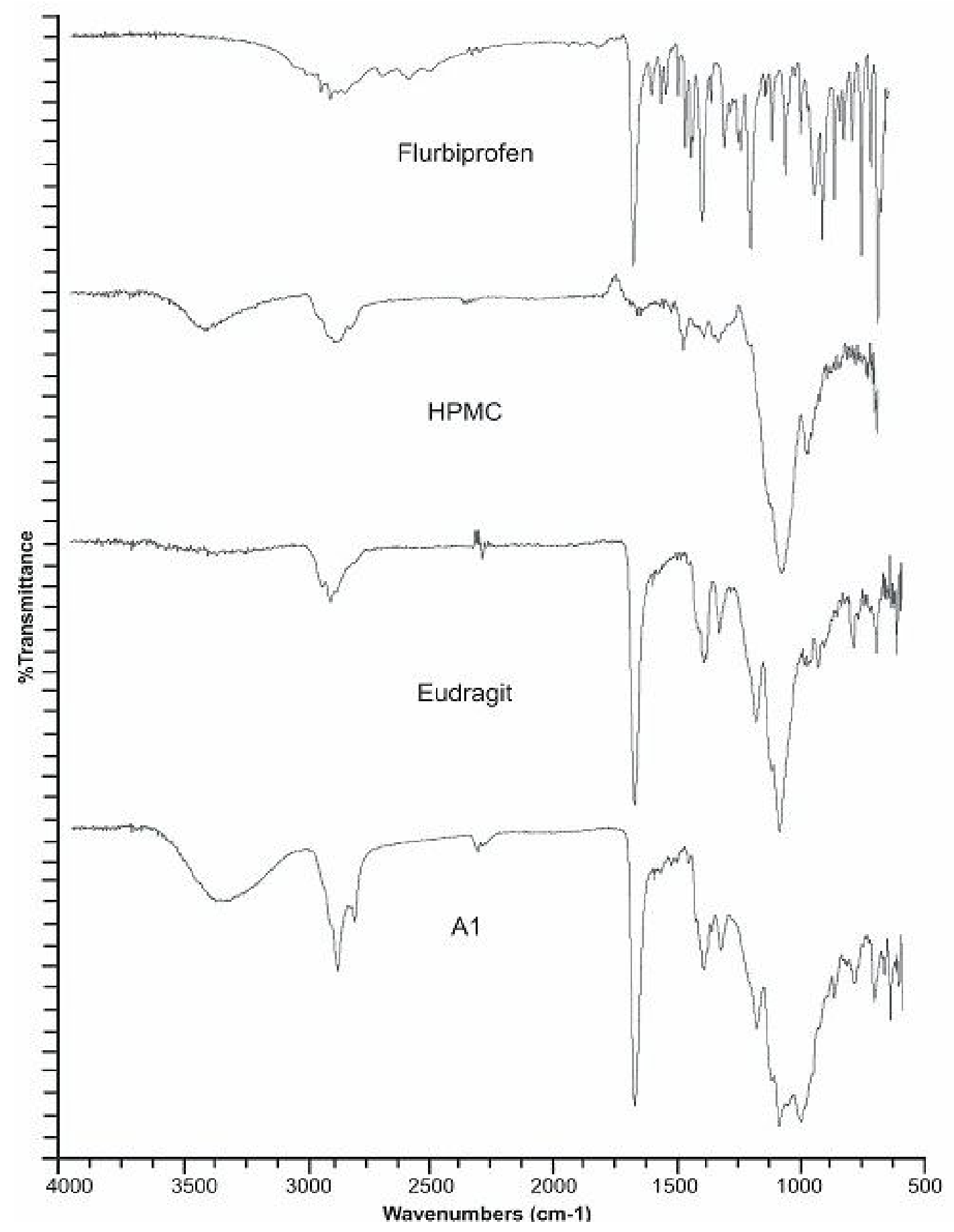

Figure 2: FT-IR spectrum of flurbiprofen, HPMC, Eudragit and formulation A1

\section{Thermal properties}

Thermal analysis was performed to check the stability and compatibility of the drug with polymers. Thermogram of pure flurbiprofen given in the figure above gives a sharp endothermic peak at $119.86{ }^{\circ} \mathrm{C}$. The thermograms of HPMC and Eudragit RS 100 as well as formulation A1 (Fig 3 ) showed that there is a decrease in the sharpness of the peak as clearly visible from the thermograms.

\section{Powder x-ray diffraction (PX-RD)}

The XRD pattern of flurbiprofen showed the characteristic peaks of $2 \theta$ at $30.256^{\circ}$ and $34.182^{\circ}$. XRD pattern of formulation A1 showed the characteristic peak in the same region with slight depression in the sharpness from $30.256^{\circ}$ to $29.014^{\circ}$ and $34.182^{\circ}$ to $33.453^{\circ}$ showed a little reduction in crystallinity of flurbiprofen (Figure 4). 


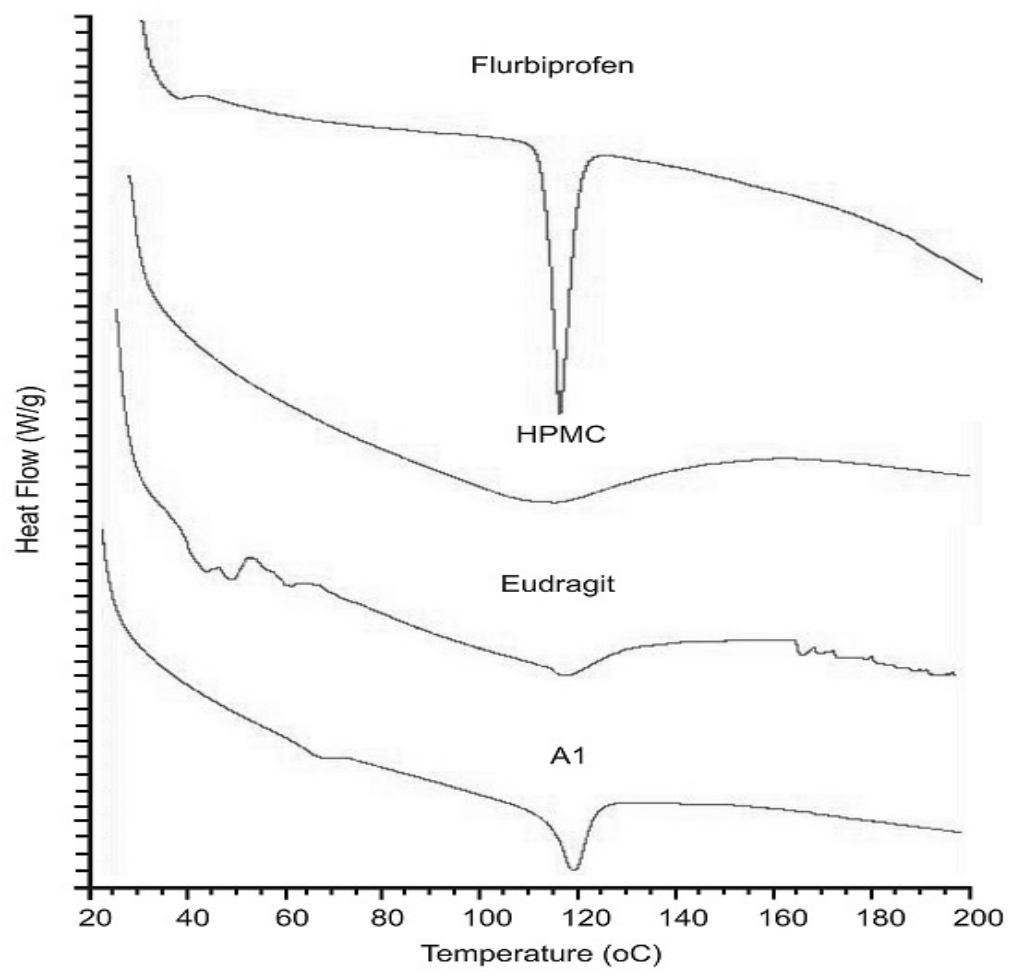

Figure 3: Thermograms of flurbiprofen, HPMC, Eudragit and formulation A1

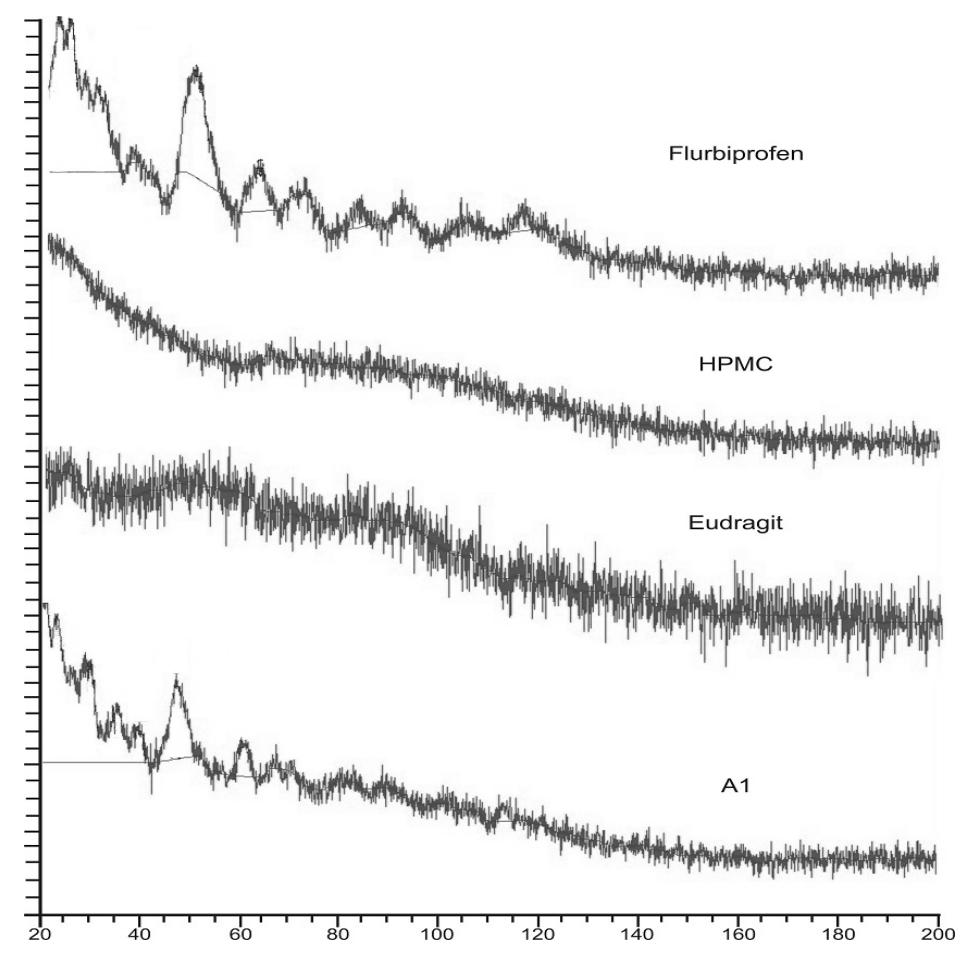

Figure 4: Powder XRD studies of Flurbiprofen, HPMC, Eudragit and Formulation A1

\section{In vitro dissolution}

The cumulative release (Figure 4 ) revealed that with an increase in drug polymer ratio, release of the formulations were decreased. It was also observed that as Eudragit RS 100 concentration increased, drug release was decreased accordingly. The formulation A1 having least Eudragit concentration gave $85.04 \%$ release whereas C3 having highest ratio gave least release of $45.77 \%$ (Fig 5). 


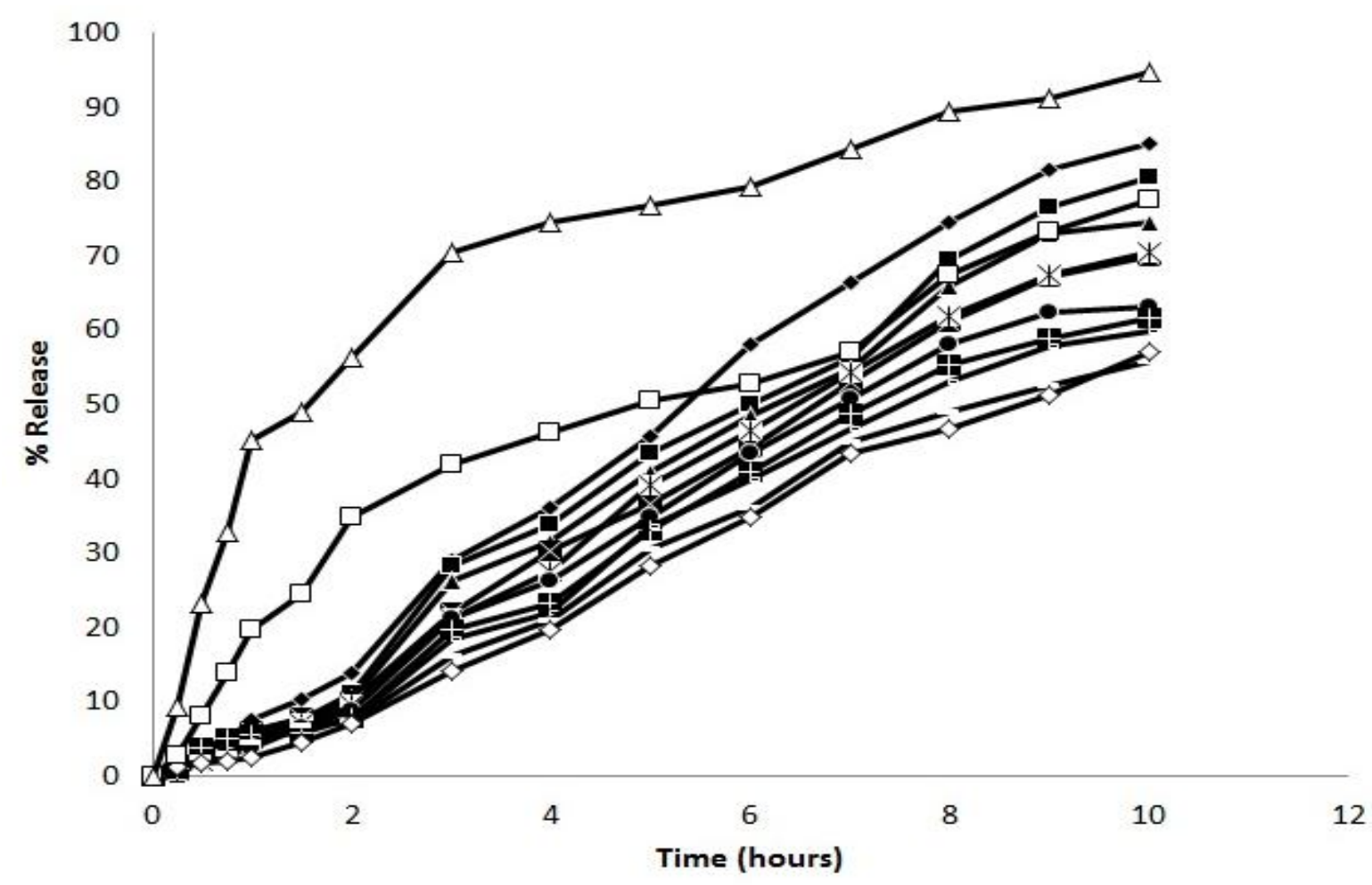

Figure 5: Cumulative drug release profiles of the formulations

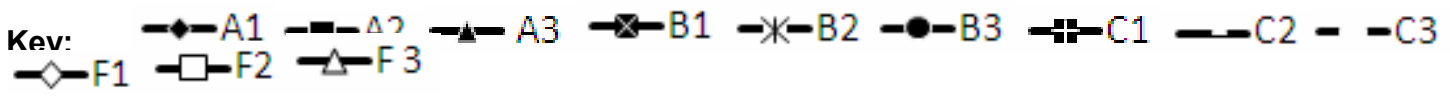

Table 5: Drug release kinetic data

\begin{tabular}{lllllllllll}
\hline & \multicolumn{2}{l}{ Zero order } & \multicolumn{3}{l}{ First order } & \multicolumn{2}{c}{ Higuchi } & \multicolumn{2}{c}{ Hixon-Crowell } & \multicolumn{2}{c}{ Korsmeyer-Peppas } \\
\cline { 2 - 11 } Formulations & $\boldsymbol{R}^{\mathbf{2}}$ & $\boldsymbol{k}_{\boldsymbol{0}}$ & $\boldsymbol{R}^{\mathbf{2}}$ & $\boldsymbol{k} \mathbf{1}$ & $\boldsymbol{R}^{\mathbf{2}}$ & $\boldsymbol{k} \boldsymbol{H}$ & $\boldsymbol{R}^{\mathbf{2}}$ & $\boldsymbol{k} \boldsymbol{C}$ & $\boldsymbol{R}^{\mathbf{2}}$ & $\boldsymbol{n}$ \\
\hline A1 & 0.9930 & 9.054 & 0.9561 & 0.142 & 0.8519 & 22.685 & 0.9760 & 0.041 & 0.9930 & 1.001 \\
A2 & 0.9912 & 8.319 & 0.9544 & 0.124 & 0.8376 & 20.757 & 0.9720 & 0.036 & 0.9919 & 1.045 \\
A3 & 0.9897 & 7.879 & 0.9594 & 0.114 & 0.8350 & 19.645 & 0.9747 & 0.034 & 0.9903 & 1.045 \\
B1 & 0.9938 & 7.328 & 0.9674 & 0.103 & 0.8423 & 18.304 & 0.9806 & 0.031 & 0.9943 & 1.039 \\
B2 & 0.9902 & 7.411 & 0.9615 & 0.105 & 0.8308 & 18.454 & 0.9757 & 0.031 & 0.9914 & 1.062 \\
B3 & 0.9865 & 6.837 & 0.9668 & 0.094 & 0.8316 & 17.043 & 0.9776 & 0.028 & 0.9871 & 1.043 \\
C1 & 0.9882 & 6.516 & 0.9673 & 0.088 & 0.8335 & 16.260 & 0.9779 & 0.027 & 0.9890 & 1.052 \\
C2 & 0.9891 & 6.328 & 0.9698 & 0.084 & 0.8336 & 15.783 & 0.9796 & 0.026 & 0.9899 & 1.053 \\
C3 & 0.9891 & 5.860 & 0.9725 & 0.076 & 0.8319 & 14.607 & 0.9809 & 0.023 & 0.9901 & 1.058 \\
F1 & 0.9861 & 5.688 & 0.9612 & 0.073 & 0.8056 & 14.062 & 0.9717 & 0.022 & 0.9924 & 1.152 \\
F2 & 0.8701 & 8.750 & 0.9678 & 0.148 & 0.9687 & 22.977 & 0.9483 & 0.042 & 0.9831 & 0.605 \\
F3 & 0.4537 & 12.147 & 0.9495 & 0.384 & 0.9372 & 33.128 & 0.8920 & 0.106 & 0.9658 & 0.395 \\
\hline
\end{tabular}

\section{Release kinetic data}

When cumulative release was subjected to kinetic modeling, all the formulations followed Korsmeyer-Peppas equation with super case II transport mechanism except F2 which followed non-Fickian transport.

\section{Similarity factor}

The similarity factor (f2) for A1, A2, A3, B1, B2 and B3 was 32, 31, 30, 30, 29 and 29 respectively, while for formulations $\mathrm{C} 1, \mathrm{C} 2, \mathrm{C} 3$, $F 1$ and F2, it was 29, 29, 28, 28 and 41 , respectively. So, the release profiles of the test formulations were different from that of the reference standard (F3). 


\section{DISCUSSION}

The results of the proposed study, presented in Table 2 showed that "F2" (Eudragit alone) produced larger particles as compared with particles of "F1" (HPMC alone). Higher concentration of Eudragit RS 100 resulted in increased viscosity of the system thus increasing the particle size $[9,10]$. FTIR spectrum of flurbiprofen showed the presence of $(C=O)$ carbonyl compound. Absorbance below $1700 \mathrm{~cm}^{-}$ 1 gives an idea of conjugation with another carbonyl group or aromatic ring [11,12]. FTIR spectrum of physical mixture showed little change in the position and sharpness of the peaks $[12,13]$. This alteration could be due to variations in the resonance structure, stretching and bending, rotation of a part of molecule or certain bonds or minor distortion of bond angle during formulation development [14]. Thermogram of pure flurbiprofen gave a sharp endothermic peak which represented the melting point of pure flurbiprofen and confirmed the crystalline structure [15]. Thermogram of HPMC and Eudragit RS 100 represented the amorphous nature of the substances. Formulation "A1" presenting a decrease in sharpness of the peak along with slight shift in temperature showing decrease in crystallinity of the substance [12]. XRD pattern of formulation A1 presented the characteristic peak in the same region with slight depression in the sharpness showed a little reduction in crystallinity of flurbiprofen. All the formulations showed a good sustained release profile. Kinetic model showing highest value of coefficient was selected as best fit model for release kinetics. All the formulations followed Korsmeyer-Peppas model with super case II transport mechanism except F2 which followed non-Fickian transport [12].

\section{CONCLUSION}

Modified emulsion solvent evaporation technique has been successfully employed for flurbiprofen microencapsulation into Eudragit RS 100 and HPMC co-polymer coats. No physical or chemical interaction was observed among the drug and polymer used. It is possible to develop a modified release formulation of flurbiprofen with minimum dose related side effects and improved patient compliance.

\section{REFERENCES}

1. Agnihotri N. Microencapsulation-A Novel Approach in Drug Delivery: A Review. Indo Glob J Pharmaceutic Sci, 2012; 2(1): 1-20.

2. Dubey R. Microencapsulation technology and applications. Defence Sci J, 2009; 59(1): 82-95.

3. Rowe RC, Sheskey PJ, Owen SC. Handbook of pharmaceutical excipients. 4TH Edition, The Pharmaceutical Press, London. 2006, p. 800-801.

4. Nikam VK. Eudragit a versitile polymer: A Review. Pharmacol. Onlin, 2011; 1: 152-164.

5. Bravo SA, Lamas MC, Salomón CJ. In-vitro studies of diclofenac sodium controlled-release from biopolymeric hydrophilic matrices. J Pharm Pharm Sci, 2002; 5(3): 213-219.

6. Sweetman CS. Martindale: The the complete drug reference. London: Royal Pharmaceutical Society. 36th edition. The Royal Pharmaceutical Press, 2009.

7. Ozbay L. Clinical study on the bioequivalence of two tablet formulations of flurbiprofen. Eur $J$ Drug MetaPharmacokin, 2009; 34(1): 1-5.

8. Ahmad M, Akhtar N, Murtaza G, Hussain SW. Formulation development and in vitro evaluation of theophylline microcapsules. Pak J Pharm Sci, 2012; 25(1): 15-19.

9. Philip PM, Arya GS. Formulation and in vitro evaluation of nelfinavir mesylate microspheres using cellulose acetate. Int JPharm Pharmaceutic Sci, 2010; 2(3): 169-171.

10. Karthikeyan J, Janardhan SJ. Saravanakumar N, Selvaraj S, Sivasakthi $R$, Mennakumari $R$, Formulation and in vitro evaluation of sustained release microspheres of Metoprolol Tartrate Loaded Eudragit-RS100. Der Pharmacia Lettre, 2010; 2(3): 261-275.

11. Coates J. Interpretation of infrared spectra, a practical approach. Encyclopedia of Analytical Chemistry, Published online: 15 Sep 2006 DOI: 10.1002/9780470027318.a5606.

12. Ranjha NM, Khan $H$, Naseem S. Encapsulation and characterization of controlled release flurbiprofen loaded microspheres using beeswax as an encapsulating agent. J Material Sci: Materials in Medicine, 2010; 21(5): 1621-1630.

13. Orlu M, Cevher E, Araman A. Design and evaluation of colon specific drug delivery system containing flurbiprofen microsponges. Int J Pharmaceutic, 2006; 318(1): 103-117.

14. Akhlaq M. Physicochemical characterization and in-vitro evaluation of flubiprofen oral controlled release matrix tablets: Role of ether derivative polymer ethocel. Afr J Pharm Pharmacol, 2011; 5(7): 862-873.

15. Varma MVK, Hemamalini K. Comparative studies on the dissolution profile of flurbiprofen from coated and uncoated alginate microspheres. Pharmacolonlin, 2007; 2: 187-202. 